\title{
Phyto-oestrogens and risk of prostate cancer in Scottish men
}

\author{
C. L. Heald ${ }^{1}$, M. R. Ritchie ${ }^{2}$, C. Bolton-Smith ${ }^{3}$, M. S. Morton ${ }^{4}$ and F. E. Alexander ${ }^{1}$ \\ ${ }^{1}$ Public Health Sciences, University of Edinburgh, Medical School, Teviot Place, Edinburgh EH8 9AG, UK \\ ${ }^{2}$ Bute Medical School, University of St Andrews, Fife KY16 9TS, UK \\ ${ }^{3} 4$ Six Mile Bottom Road, West Wratting, Cambridge CB1 5NE, UK \\ ${ }^{4}$ Department of Medical Biochemistry, College of Medicine, Cardiff University, Cardiff CF14 4XN, UK
}

(Received 28 August 2006 - Revised 8 January 2007 - Accepted 29 January 2007)

\begin{abstract}
A population-based case-control study of diet, inherited susceptibility and prostate cancer was undertaken in the lowlands and central belt of Scotland to investigate the effect of phyto-oestrogen intake and serum concentrations on prostate cancer risk. A total of 433 cases and 483 controls aged 50-74 years were asked to complete a validated FFQ and provide a non-fasting blood sample. Multivariate logistic regression analysis found significant inverse associations with increased serum concentrations of enterolactone (adjusted OR 0.40, $95 \%$ CI 0.22, 0.71] and with the consumption of soy foods (adjusted OR 0.52, $95 \%$ CI 0.30, 0.91). However, no significant associations were observed for isoflavone intake or serum genistein, daidzein and equol. This study supports the hypotheses that soy foods and enterolactone metabolised from dietary lignans protect against prostate cancer in older Scottish men.
\end{abstract}

Prostate cancer: Phyto-oestrogens: Isoflavones: Lignans: Soy foods

Prostate cancer (PCa) is an important and increasing public health problem in Scotland. It is the second most common cancer in men after lung cancer, and accounts for $10 \%$ of all male cancer-related deaths (Kirk \& Alexander, 2001). Within the last three decades, PCa incidence in Scotland has more than doubled (Kirk \& Alexander, 2001), with 2335 cases of PCa diagnosed in 2002 (ISD Scotland, 2004). The relatively low risk of $\mathrm{PCa}$ in Asian populations compared with Western countries, including Scotland, suggests that dietary factors may influence the prevalence of and mortality from this disease (Armstrong \& Doll, 1975; Muir et al. 1991; Parkin \& Muir, 1992; Maskarinec et al. 1998). Of special interest is the group of plant-derived nutrients called phyto-oestrogens, in particular isoflavones (genistein, daidzein and equol) and lignans (enterolactone and enterodiol).

Isoflavones are found mainly in soybeans and soy products (Coward et al. 1993; Kuzer \& Xu, 1997; Mazur, 1998; Murphy et al. 1999; Horn-Ross et al. 2000b), foods that are consumed in far greater amounts by populations in Asia compared with those in Western countries (Chen et al. 1999; Wakai et al. 1999). In Western countries, soy foods tend to be eaten most frequently by vegetarians and vegans (Chen et al. 1999; Arai et al. 2000). Isoflavone precursors are metabolised by the gut microflora to give rise to compounds such as daidzein, genistein and equol (Griffiths et al. 1998). Another group of phyto-oestrogens are the lignans; they are derived from the plant precursors matairesinol and secoisolariciresinol which are present in a wide variety of plant foods, including linseed, legumes, cereals, fruits and vegetables (Mazur, 1998; Liggins et al. 2000c). These plant precursors are metabolised by gut microflora into the lignans enterolactone and enterodiol.

The relevant biological properties of phyto-oestrogens include antiviral, antiangiogenic and antioxidant properties (Griffiths et al. 1998). Phyto-oestrogens possess weak oestrogenic activity, they compete with oestradiol in binding to the nuclear oestrogen receptor and also stimulate the synthesis of sex hormone-binding globulin, which in turn mediates the plasma levels of testosterone on which the growth, development, maintenance and function of the prostate gland is dependent. In addition, phyto-oestrogens can inhibit steroidmetabolising enzymes, including $5 \alpha$-reductase and aromatase, and also the cell signalling apparatus by the inhibition of tyrosine-specific protein kinases (Griffiths et al. 1998).

Several epidemiological studies support the role of phytooestrogens and soy foods in reducing cancer risk (Adlercreutz \& Mazur, 1997, Yan \& Spitznagel, 2005). However, this evidence is limited, in particular for PCa, with only a few studies examining this association usually in populations with high isoflavone/soy food consumption (Mills et al. 1989; Severson et al. 1989; Jacobsen et al. 1998; Kolonel et al. 2000; Akaza et al. 2002; Lee et al. 2003; Ozasa et al. 2004).

The association of phyto-oestrogen intake and PCa risk has been difficult to study due to a lack of a suitable and comprehensive phyto-oestrogen food database. Recently, several phyto-oestrogen databases have been created (Pillow et al.

\footnotetext{
Abbreviations: BPH, benign prostatic hyperplasia; BrCA, breast cancer; EI, energy intake; PCa, prostate cancer; SCG-FFQ, Scottish Collaborative Group-FFQ. * Corresponding author: Dr M. R. Ritchie, fax +44 (0) 1334 4634, email mrr3@st-andrews.ac.uk
} 
1999; USDA, 1999; Horn-Ross et al. 2000a; Venus Phyto-oestrogen Database, 2004). However, these databases, mainly created in the USA, are not comprehensive enough to be used to assess the dietary impact of phyto-oestrogens in the UK. This study uses a recently created and validated isoflavone food database (Ritchie, 2004; Ritchie et al. 2004, 2005) which is based on foods normally consumed in Scotland.

The first aim of this study was to define the distributions of the estimated dietary intake of isoflavones, and serum concentrations of the main isoflavones daidzein and genistein, the isoflavan equol and the lignan enterolactone in older men participating in the PCANDIET study, a case-control study of $\mathrm{PCa}$, inherited susceptibility and diet. The second aim was to examine the association between phyto-oestrogen intake and serum concentrations and PCa. To our knowledge, this is the first time the association between phyto-oestrogens and $\mathrm{PCa}$ has been investigated within a UK male population.

\section{Methods}

\section{Subjects}

The PCANDIET Study, a population-based epidemiological case-control study of $\mathrm{PCa}$ in relation to inherited susceptibility and diet, was carried out in the lowlands and central belt of Scotland. This report focuses on the dietary side of this study, in particular phyto-oestrogens. The study population included men aged 50-74 years who resided in the Borders, Lothian and Greater Glasgow Health Board areas. Between April 1998 and December 2001, we attempted to identify all men newly diagnosed with histologically confirmed clinically important PCa (defined as grade $>$ T1a and Gleason score $>4$ ) at hospitals within the Lothian, Borders and Glasgow Health Boards (Western General Hospital, Edinburgh; Borders General Hospital, Melrose; Glasgow Royal Infirmary; Stobhill Hospital, Glasgow; Victoria Infirmary, Glasgow; Southern General Hospital, Glasgow; Gartnavel General Hospital, Glasgow; and St John's Hospital, Livingston). Population controls, frequency matched by age and Health Board to cases, were randomly selected from Health Board Lists (Lothian and Borders Health Boards) and GP lists (Glasgow Health Board). In addition, all men newly diagnosed with benign prostatic hyperplasia (BPH) between April 1998 and December 2001 at the Western General Hospital, Edinburgh and Borders General Hospital, Melrose were identified, in order to be used as a second control group. The study was restricted to men who were mentally capable of completing a questionnaire and who had no previous diagnosis of PCa.

Subjects were invited to participate in the study after receiving permission to contact them from their consultant (cases and BPH controls) or GP (population controls). After providing written consent to participate in the study, the subjects were asked to complete the Scottish Collaborative Group FFQ (SCG-FFQ) and to provide a non-fasting blood sample.

\section{Dietary assessment}

A copy of the SCG-FFQ was posted to each subject for self-completion. Guidelines for completing the questionnaire and photographic information on the size of portions were also included, and advice on completing the SCG-FFQ was available by FreePhone.

The SCG-FFQ has been used extensively in Scotland (BoltonSmith et al. 1995; Sharp et al. 2002) and has been validated against serum isoflavones (Heald et al. 2005) and $4 \mathrm{~d}$ weighed diet records for adequacy of macro and some micronutrient intakes (Masson et al. 2003). It focused on dietary habit during the past 2-3 months and specified 155 food items accounting for 600 individual foods. For each of these food items, the respondent was asked to select from nine categories (ranging from 'rarely/never' to '7 days per week') the number of days per week the food item was eaten, and also to indicate their usual portion size by selecting from five categories (ranging from 1 to $5+$ measures per day). The SCG-FFQ also contained questions on the type and amount of vitamins, minerals and food supplements taken, and dietary change and special diets/dietary restrictions, and included a section for other foods eaten which the respondent had not already included elsewhere.

All SCG-FFQs were reviewed for completeness. Data from the reviewed SCG-FFQs were processed using the scanning software package TELEForm (version 5.2, Cardiff Software, Inc., San Marcos, CA, USA) and software based on the Oracle Relational Database Management System (Version 7), which has been developed and routinely used at the University of Aberdeen. Estimated intake of specific nutrients and micro-nutrients was computed using McCance and Widdowson's The Composition of Foods (5th ed.) (Holland et al. 1991b) and related supplements (Holland et al. 1988, 1989, 1991a, 1992a,b, Holland et al. 1993; Chan et al. 1994, 1995, 1996).

Food values for the isoflavones daidzein and genistein were obtained from the newly constructed (Ritchie, 2004; Ritchie et al. 2005) and validated (Ritchie et al. 2004) Isoflavone Food Database that contains isoflavone values for nearly 7000 foods. It incorporates foods analysed by Liggins et al. $(2000 a, b)$ and isoflavone estimates for soy flour and protein added as bulking agents during food processing. Isoflavone contents were assigned to each of the 155 food items using the new database. Two specific food items for soy foods were included that named the following foods as soy food examples: (1) soya beans, textured vegetable protein (TVP), tofu and soya meat substitute; and (2) nut roast, nut burgers and vegetable burgers. Soya milk and other soy-based foods reported in the 'Other Foods' section were also included in the assessment of isoflavone intake.

\section{Blood sample collection and analysis}

Non-fasting blood samples were collected at the subjects' GP practice or by a research nurse. A $20 \mathrm{ml}$ aliquot of peripheral blood was collected in a vacuum syringe using the Vacutainer $^{\circledR}$ system and sent to the BioClin Laboratories, Cardiff for storage and analysis.

A subgroup containing the first 454 blood samples received at BioClin Laboratories were analysed for serum phyto-oestrogens. Isotope dilution gas chromatography-mass spectrometry (GC-MS) was used to analyse the isoflavones genistein and daidzein, the daidzein metabolite equol and the lignan enterolactone in serum (Morton et al. 1994). The detection limit for each of the four assays was $0.1 \mathrm{mg} / 1$ (daidzein, $0.394 \mathrm{nmol} / \mathrm{l}$; genistein, $0 \cdot 370 \mathrm{nmol} / 1$; and equol, $0.417 \mathrm{nmol} / 1)$; data below these limits were regarded as zero (Morton et al. 2002). 


\section{Statistical analysis}

All statistical analyses were conducted using SPSS (version 11, SPSS Inc., Chicago, IL, USA) and STATA (version 7, STATA Inc., College Station, TX, USA). Distribution analysis was performed on intakes of isoflavones, total energy and soy food groups, phyto-oestrogen serum concentrations (genistein, daidzein, equol and enterolactone) and general anthropometric characteristics (including age, height, weight, BMI, BMR (Schofield, 1985) and the energy intake:BMR ratio (EI:BMR) (Goldberg et al. 1991)). As the distributions of phyto-oestrogen intake and serum concentrations in the study population were markedly skewed, medians were quoted and non-parametric tests were used to estimate differences in cases and controls. A comparison of the population and BPH controls showed that there were no significant differences in either phyto-oestrogen intake and serum concentration or general subject characteristics, with the exception of age, between these two control groups; therefore the two control groups were combined. OR and $95 \%$ CI were calculated using logistic regression for four categories of intake/ serum concentration using quartiles based on the distribution of controls, with the exception of soy food consumption which used two categories (consumption of soy foods $v$. no consumption of soy foods). Adjusted OR for isoflavone intake and soy food consumption were controlled for age group, total energy intake category, family history of $\mathrm{PCa}$ and/or breast cancer (BrCa), Carstairs Deprivation Index (a deprivation index by Carstairs \& Morris, 1991, based on the 1991 census data), smoking status and the EI:BMR ratio, by including these potential confounders as co-variates in the multivariate logistic regression models. Energy-adjusted intakes for isoflavones and soy foods were also calculated using the residual method (Willett \& Stampfer, 1998); these produced findings similar to those for the multivariate logistic regression model and therefore were not presented. Adjusted OR for serum phyto-oestrogens were controlled for age group, family history of $\mathrm{PCa}$ and/or $\mathrm{BrCa}$, Carstairs Deprivation Index and smoking. Score tests for a linear trend were also conducted to examine any potential dose-response effects.

\section{Results}

A total of 604 eligible cases and 911 eligible controls were approached. Of these, 433 cases and 483 controls (including 305 population controls and $178 \mathrm{BPH}$ controls) completed an SCG-FFQ and provided a blood sample. Blood samples from the first 454 subjects to provide a blood sample (249 cases and 205 controls) were analysed for serum phyto-oestrogens. A total of 916 subjects were therefore included in this study, all of which were included the nutrient/food consumption analysis, whereas 454 subjects were included in the subset analysis of serum phyto-oestrogens.

\section{Subject characteristics}

As shown in Table 1, there was very little variation in subject characteristics between cases and controls, with the exception of mean age where cases were significantly older than controls. This difference is due to the inclusion of BPH controls that were not age frequency matched to cases, unlike population controls. The EI:BMR ratio was also significantly higher in the cases, suggesting either that cases consumed more food than necessary (thereby suggesting that overconsumption is associated with increased risk of PCa) or that the controls were under-reporting. As BMI did not differ significantly between cases and controls, the latter seems more likely; this was confirmed by the proportion of low energy responders (subjects who under-reported food consumption) being significantly higher within the control group (Table 1). There was no significant variation in either smoking status or deprivation index between cases and controls; however, significantly more cases reported a family history of PCa and/or BrCa than controls.

\section{Phyto-oestrogen intake and serum concentrations}

The distributions of total energy and phyto-oestrogen intake, and phyto-oestrogen serum concentrations are shown in Table 2. For each of the four serum phyto-oestrogens measured, the minimum value was below the level of detection $(0.1 \mathrm{mg} / \mathrm{l})$. Data for both equol and daidzein serum concentrations were missing for five subjects, whereas genistein serum concentration data were missing for seven subjects.

Mean total energy intake was significantly lower in controls than cases; phyto-oestrogen intake was also observed to be slightly lower in controls, although this difference was not significant. There were no significant differences in phyto-oestrogen serum concentrations between cases and controls, except for enterolactone, the serum concentrations for which were found to be significantly greater within the control group. Equol was detected in 121 cases $(49 \%)$ (median $0.98 \mathrm{nmol} / \mathrm{l}$, interquartile range (IQR) $0.51-1.84$ ) and 98 controls (49\%) (median $0.67 \mathrm{nmol} / \mathrm{l}$, IQR $0.34-1.51$ ). Overall, there was great interindividual variation in serum isoflavones, with an 8500- and 270-fold variation between minimum and maximum values in cases and controls, respectively. Serum enterolactone concentrations also varied considerably, with a 1900- and 300-fold variation in cases and controls, respectively. The variation in estimated dietary intake of isoflavones (daidzein and genistein) was also large, from 0.01 to $21.26 \mathrm{mg}$ / $\mathrm{d}$ and from 0.01 to $42.99 \mathrm{mg} / \mathrm{d}$ for cases and controls, respectively. Consumption of soy foods was relatively low, with only $7.2 \%$ of subjects reporting eating soy foods.

\section{Association with PCa risk}

Crude and adjusted OR for phyto-oestrogen intake and serum concentrations are shown in Table 3. Phyto-oestrogen intake was observed to have no association with PCa risk, with risk estimates remaining close to null for all levels of intake. However, the consumption of soy foods was shown to have a significant protective association against $\mathrm{PCa}$, which became slightly stronger when confounding factors were adjusted for (adjusted OR 0.52, $95 \%$ CI $0.30,0.91$ ). No significant associations were observed for phyto-oestrogen serum concentrations, with the exception of enterolactone for which significant protective associations were observed for all categories of serum concentrations compared with the lowest category, both with and without adjusting for potential confounding factors (adjusted OR for highest 
Table 1. Subject characteristics by subject status

\begin{tabular}{|c|c|c|c|}
\hline & Cases $^{*}(n$ 433) & Controls $^{*}(n 483)$ & $\begin{array}{l}\text { Test for difference between } \\
\text { cases and controls } \dagger(P \text { value) }\end{array}$ \\
\hline Age (years) & $67 \cdot 2(5 \cdot 5)$ & $66.0(5.4)$ & 0.001 \\
\hline Height (m) & $1.74(0.08)$ & $1.74(0.07)$ & 0.91 \\
\hline Weight (kg) & $79.8(13.4)$ & $79 \cdot 1(12 \cdot 1)$ & 0.40 \\
\hline BMI & $26 \cdot 3(4 \cdot 0)$ & $26.1(3.6)$ & 0.37 \\
\hline El:BMR & $1.59(0.50)$ & $1.51(0.50)$ & 0.03 \\
\hline \multicolumn{4}{|l|}{ Family history of cancer } \\
\hline No family history of $\mathrm{PCa}$ or $\mathrm{BrCa}$ & $298(69)$ & $387(80)$ & 0.001 \\
\hline Family history of $\mathrm{PCa}$ & $60(14)$ & $38(8)$ & \\
\hline Family history of $\mathrm{BrCa}$ & $58(13)$ & $48(10)$ & \\
\hline Family history of $\mathrm{PCa}$ and $\mathrm{BrCa}$ & $17(4)$ & $10(2)$ & \\
\hline \multicolumn{4}{|l|}{ Smoking } \\
\hline Non-smoker & $175(41)$ & $229(48)$ & $0 \cdot 11$ \\
\hline Ex-smoker & $174(41)$ & $168(35)$ & \\
\hline Smoker & 76 (18) & $79(17)$ & \\
\hline \multicolumn{4}{|l|}{ LER } \\
\hline Yes & $62(15)$ & $95(20)$ & 0.03 \\
\hline No & $359(85)$ & $371(80)$ & \\
\hline \multicolumn{4}{|l|}{ Carstairs Deprivation Index } \\
\hline 1 & $69(16)$ & $66(14)$ & 0.87 \\
\hline 2 & $64(15)$ & $73(15)$ & \\
\hline 3 & $97(23)$ & $103(22)$ & \\
\hline 4 & $75(18)$ & $93(20)$ & \\
\hline 5 & $54(13)$ & $69(15)$ & \\
\hline 6 & $31(7)$ & $33(7)$ & \\
\hline 7 & $37(9)$ & $35(7)$ & \\
\hline
\end{tabular}

El:BMR, energy intake:BMR ratio; $\mathrm{PCa}$, prostate cancer; BrCa, breast cancer; LER, low energy responder.

*Values for age, height, weight, BMI and El:BMT ratio are means (SD), values for family history of cancer, smoking, LER and Carstairs Deprivation Index are frequencies (\%).

† Using $t$ test for age, height, weight, BMI and El:BMR ratio, and $\chi^{2}$ test for family history of cancer, smoking, LER and Carstairs Deprivation Index Percentages may not add up to $100 \%$ due to rounding.

serum category $=0.40,95 \%$ CI $0.22,0.71)$ and for which a significant dose-response effect was found $(P=0 \cdot 002)$.

\section{Discussion}

In this case-control study, a significant protective effect of serum enterolactone against PCa was observed. The findings for isoflavones were less clear. No association with PCa risk was observed for either serum isoflavones or isoflavone intake; however, consumption of soy foods was observed to be associated with a significant decrease in PCa risk.

The point estimate of a $60 \%$ reduction in PCa risk associated with high concentrations of serum enterolactone observed in this study is not in agreement with the three previous nested case-control studies that reported no significant associations between serum enterolactone and PCa risk in Scandinavian men (Stattin et al. 2002, 2004; Kilkkinen et al. 2003). One possible reason for the lack of significant associations observed in these previous studies is that the relatively low enterolactone serum levels reported in all three studies (median: 8.4 and $8.5 \mathrm{nmol} / 1$ for cases and controls, respectively (Stattin et al. 2002), compared with 11.78 and $16 \cdot 16 \mathrm{nmol} / \mathrm{l}$ for cases and controls in this study) were too low for a protective effect to be observed. Also, the long storage times of the serum samples reported by Stattin et al. (2002) (a large proportion of samples were stored for $>20$ years) could have allowed for the degradation of serum enterolactone, thereby leading to a possible random misclassification of enterolactone concentrations which in turn may have caused an attenuation of the risk estimates towards the null. Furthermore, Kilkkinen et al. (2003) examined serum enterolactone in a population comprised only of smokers. Not only does the inclusion of only smokers restrict the generalisability of the findings, but smoking is associated with both lower levels of serum enterolactone (Kilkkinen et al. 2001) and an increased risk of fatal PCa (Hsing et al. 1990, 1991). It is therefore possible that the serum enterolactone concentrations reported in this study were high and varied enough for the true protective association to be detected. Although no significant association between the intake of enterolactone precursors and $\mathrm{PCa}$ risk has been reported (Strom et al. 1999), our findings are supported by a cohort study of Adventist men (Mills et al. 1989) and three casecontrol studies (Key et al. 1997; Kolonel et al. 2000; Hodge et al. 2004) undertaken in Western populations including the UK (Key et al. 1997), which identified consumption of foods rich in enterolactone precursors, such as beans, peas and lentils, as being significantly associated with a protective effect against $\mathrm{PCa}$.

Consumption of soy foods was associated with a $50 \%$ reduction in $\mathrm{PCa}$ risk in this study. This finding is similar to those of two prospective studies on men of Japanese ancestry living in Hawaii (Severson et al. 1989) and Californian Seventh-day Adventist men (Jacobsen et al. 1998) who reported that men who consumed tofu more than five times a week (Severson et al. 1989) or soy milk more than once a day (Jacobsen et al. 1998) had a $65 \%$ (Severson et al. 1989) and $70 \%$ (Jacobsen et al. 1998) reduction in $\mathrm{PCa}$ risk, respectively. Several case-control studies, conducted within populations with high soy consumption, have also 
confirmed this association (Kolonel et al. 2000; Lee et al. 2003; Chen et al. 2005). In contrast, a large Canadian study (Villeneuve et al. 1999) did not detect any association between soy food consumption and PCa risk. In addition, a recent meta-analysis (Yan \& Spitznagel, 2005) conducted on eight studies that examined the association between soy consumption and $\mathrm{PCa}$ reported an overall risk estimate of 0.70 (95\% CI $0.59,0.83, P<0.001)$. The relatively low consumption of soy foods meant that further analyses on soy food consumption to investigate linear trend was not possible.

However, this study observed no significant associations between either isoflavone intake or serum concentrations and $\mathrm{PCa}$ risk. No association was observed for isoflavone intake $(\mathrm{OR}=1.18,95 \% \mathrm{CI} 0.41,2.25)$; this is different from the findings of two case-control studies on Caucasian US men (Strom et al. 1999) and Chinese men (Lee et al. 2003) which reported a protective trend against PCa for both genistein and daidzein intake. However, of these, only the association for genistein intake within the Chinese men was found to be significant (Lee et al. 2003). Daily isoflavone intake within the Chinese study (Lee et al. 2003) was $76 \mathrm{mg}$; this is seventy times greater than the daily intake observed in this study (1.1 mg/d) and also by Strom et al. (1999) $(1.2 \mathrm{mg} / \mathrm{d})$. It is very possible that the intake of isoflavones observed in this study was not high enough for a protective effect to be detected. No significant associations between serum isoflavones and $\mathrm{PCa}$ risk were found in this study. These findings are similar to those of Akaza et al. (2002) who observed no significant difference in either daidzein or genistein serum concentrations between cases and controls within a Japanese population. The only other study to examine the association between serum isoflavones and PCa (Ozasa et al. 2004) reported a non-significant dose-dependent protective association for both daidzein and genistein serum concentrations, and a significant protective association for both equol (OR 0.39, $95 \%$ CI $0 \cdot 15,0.98$ ) and combined equol/daidzein (OR $0.35,95 \%$ CI $0 \cdot 13,0.89$ ).

As with all case-control studies, this study was subjected to several methodological limitations. The methods used in the selection and recruitment of this study allowed for potential bias and confounding to be limited. The overall response rate was observed to be $67 \%$. The response rate differed between cases and controls (80 and $63 \%$, respectively); it is therefore possible that bias may have been introduced into the study. However, analysis of response rates showed that the observed trend towards younger subjects and those with lower levels of deprivation being more likely to respond were similar in both cases and controls. In order to protect against disease/subject misclassification, all cases were histologically confirmed as having PCa. In addition, the use of $\mathrm{BPH}$ controls ensured that a large proportion of controls were confirmed as unlikely to have asymptomatic PCa. Also, the combining of the two control groups (which had similar distributions of phyto-oestrogen serum and intake and confounding factors, and were observed to have similar risk estimates when compared with cases separately) increased the statistical power of the study. The use of BPH controls could introduce selection bias if $\mathrm{BPH}$ is associated with $\mathrm{PCa}$ risk; however, to date, no evidence for this association has been reported (Guess, 2001). To minimise recall bias, only 
Table 3. Logistic regression analysis - crude and adjusted OR

\begin{tabular}{|c|c|c|c|c|c|c|}
\hline & \multicolumn{2}{|c|}{ Frequency } & \multicolumn{2}{|c|}{ Crude OR } & \multicolumn{2}{|c|}{ Adjusted OR* } \\
\hline & Case $(n)$ & Control $(n)$ & OR & $(95 \% \mathrm{Cl})$ & OR & $(95 \% \mathrm{Cl})$ \\
\hline \multicolumn{7}{|c|}{ Total energy intake $(\mathrm{kJ} / \mathrm{d})$} \\
\hline $0-7874$ & 87 & 121 & 1.00 & - & 1.00 & - \\
\hline $7874-9684$ & 105 & 121 & 1.21 & $(0.82,1.77)$ & 1.02 & $(0.59,1.76)$ \\
\hline $9684-11757$ & 106 & 121 & 1.22 & $(0.83,1.78)$ & 1.03 & $(0.53,2.01)$ \\
\hline$>11757$ & 135 & 120 & 1.56 & $(1.08,2 \cdot 27)$ & 0.96 & $(0.41,2.25)$ \\
\hline \multicolumn{7}{|c|}{$\begin{array}{l}\text { Score test for linear trend: } P=1.00 \dagger \\
\text { Isoflavone intake }(\mu \mathrm{g} / \mathrm{d})\end{array}$} \\
\hline $0-581 \cdot 1$ & 95 & 121 & 1.00 & - & 1.00 & - \\
\hline $581 \cdot 1-1050 \cdot 9$ & 100 & 121 & 1.05 & $(0.72,1.54)$ & 1.12 & $(0.76,1.67)$ \\
\hline $1050 \cdot 9-1982 \cdot 8$ & 112 & 121 & $1 \cdot 18$ & $(0.81,1.71)$ & $1 \cdot 11$ & $(0.75,1.65)$ \\
\hline$>1982 \cdot 8$ & 126 & 120 & $1 \cdot 34$ & $(0.93,1.93)$ & $1 \cdot 18$ & $(0.79,1.75)$ \\
\hline \multicolumn{7}{|c|}{ Score test for linear trend: $P=0.87 \dagger$} \\
\hline \multicolumn{7}{|c|}{ Soy food consumption } \\
\hline No & 410 & 440 & 1.00 & - & 1.00 & - \\
\hline Yes & 23 & 43 & 0.57 & $(0.34,0.97)$ & 0.52 & $(0.30,0.91)$ \\
\hline \multirow{2}{*}{\multicolumn{7}{|c|}{ Score test for linear trend: $P=0.34 \dagger$}} \\
\hline \multicolumn{2}{|c|}{ Serum equol $(\mathrm{nmol} / \mathrm{l})$} & & & & & \\
\hline 0 & 126 & 102 & 1.00 & - & 1.00 & - \\
\hline$\geq 0.10$ & 121 & 98 & 1.00 & $(0.69,1.45)$ & 1.07 & $(0.71,1.61)$ \\
\hline \multicolumn{7}{|c|}{ Score test for linear trend: $P=0.75 \dagger$} \\
\hline \multicolumn{7}{|c|}{ Serum daidzein $(\mathrm{nmol} / \mathrm{l})$} \\
\hline $0.00-8.26$ & 51 & 47 & 1.00 & - & 1.00 & - \\
\hline $8.26-18.00$ & 74 & 53 & 1.29 & $(0.76,2.19)$ & $1 \cdot 20$ & $(0.67,2.14)$ \\
\hline $18 \cdot 00-29 \cdot 11$ & 44 & 51 & 0.80 & $(0.45,1.40)$ & 0.74 & $(0.40,1.37)$ \\
\hline$>29 \cdot 11$ & 78 & 49 & 1.47 & $(0.86,2.51)$ & 1.34 & $(0.76,2.38)$ \\
\hline \multicolumn{7}{|c|}{ Score test for linear trend: $P=0.21 \dagger$} \\
\hline \multicolumn{7}{|c|}{ Serum daidzein and equol combined (nmol/l) } \\
\hline $0.00-8.48$ & 47 & 50 & 1.00 & - & 1.00 & - \\
\hline $8.48-18.66$ & 81 & 50 & 1.72 & $(1.01,2.95)$ & 1.79 & $(1.00,3.20)$ \\
\hline $18.66-33.69$ & 54 & 50 & $1 \cdot 15$ & $(0.66,2.00)$ & 1.01 & $(0.56,1.85)$ \\
\hline$>33.69$ & 65 & 50 & 1.38 & $(0.80,2.39)$ & 1.34 & $(0.75,2 \cdot 40)$ \\
\hline \multicolumn{7}{|c|}{ Score test for linear trend: $P=0.14 \dagger$} \\
\hline \multicolumn{7}{|c|}{ Serum genistein $(\mathrm{nmol} / \mathrm{l})$} \\
\hline $0.00-14.23$ & 49 & 49 & 1.00 & - & 1.00 & - \\
\hline $14.23-33.46$ & 68 & 50 & 1.36 & $(0.79,2.34)$ & 1.38 & $(0.76,2.50)$ \\
\hline $33.46-64.53$ & 48 & 50 & 0.96 & $(0.55,1.68)$ & 0.90 & $(90.49,1.67)$ \\
\hline$>64.53$ & 73 & 49 & 1.49 & $(0.89,2.56)$ & 1.36 & $(0.76,2.43)$ \\
\hline \multicolumn{7}{|c|}{ Score test for linear trend: $P=0.37 \dagger$} \\
\hline \multicolumn{7}{|c|}{ Serum enterolactone $(\mathrm{nmol} / \mathrm{l})$} \\
\hline $0.00-8.41$ & 108 & 50 & 1.00 & - & 1.00 & - \\
\hline $8 \cdot 41-16 \cdot 16$ & 40 & 50 & 0.37 & $(0.21,0.64)$ & 0.43 & $(0.24,0.76)$ \\
\hline $16 \cdot 16-28 \cdot 90$ & 53 & 50 & 0.49 & $(0.29,0.83)$ & 0.47 & $(0.27,0.81)$ \\
\hline$>28.90$ & 46 & 50 & 0.43 & $(0.25,0.73)$ & 0.40 & $(0.22,0.71)$ \\
\hline \multicolumn{7}{|c|}{ Score test for linear trend: $P=0.002 \dagger$} \\
\hline \multicolumn{7}{|c|}{ Total serum isoflavones $\ddagger(\mathrm{nmol} / \mathrm{l})$} \\
\hline $0.00-25.57$ & 54 & 49 & 1.00 & - & 1.00 & - \\
\hline $25 \cdot 57-50.52$ & 63 & 50 & $1 \cdot 14$ & $(0.67,1.96)$ & 1.09 & $(0.60,1.96)$ \\
\hline $50.52-98.86$ & 49 & 50 & 0.89 & $(0.51,1.55)$ & 0.85 & $(0.46,1.55)$ \\
\hline$>98.86$ & 72 & 49 & 1.33 & $(0.78,2 \cdot 27)$ & 1.24 & $(0.69,2.20)$ \\
\hline \multicolumn{7}{|c|}{ Score test for linear trend: $P=0.64 \dagger$} \\
\hline
\end{tabular}

* Isoflavone intake and soy food consumption adjusted for age, total energy intake, family history of $\mathrm{PCa}$ and $\mathrm{BrCa}$, Carstairs Deprivation Index, smoking and energy intake:BMR ratio. Serum phyto-oestrogens adjusted for age, family history of prostate cancer and breast cancer, Carstairs Deprivation Index and smoking. † Adjusted OR.

‡Total isoflavones = daidzein, genistein and equol.

newly diagnosed cases were used. However, due to recent media attention on the benefits of soy foods, it is still possible that not only did some cases recall their dietary habits differently, but also that they could have changed their diets post-diagnosis to increase consumption of these foods. This could lead to differential misclassification of isoflavone and soy food intake, and may be the reason behind why a slight positive association with PCa risk was observed in the highest categories of both isoflavone intake and serum concentrations.
The self-completion of the SCG-FFQ allowed for observer bias to be minimised. The use of SCG-FFQ, which has been validated against serum isoflavones within the population under study (Heald et al. 2005), and the new comprehensive Isoflavone Food Database - constructed and validated within the target population under study (Ritchie, 2004; Ritchie et al. 2004) - also allowed for accurate estimations of isoflavone intake, thereby minimising any further potential misclassification of intake. 
To minimise the effects of potential confounders, known risk factors were included in the multivariate regression model; however it is likely that residual confounding due to unmeasured or unknown factors may have remained. It is possible that dietary co-variates of phyto-oestrogens may be responsible for the observed associations with PCa risk. As the plant precursors of enterolactone are predominantly found in whole-grain products, legumes, seeds, fruits and vegetables, it may be that serum enterolactone is a proxy for a general healthy diet. This could also be the case for soy foods, as this food group is also associated with a healthy diet rich in fruit and vegetables and low in animal products - a dietary factor observed to increase PCa risk (Kolonel, 2001). In addition to dietary intake, serum phyto-oestrogen levels are also influenced by gut microflora metabolism and absorption from the gut (Rowland et al. 1999, 2000; Kilkkinen et al. 2001). Absorption and metabolism of phyto-oestrogens has been reported to be influenced by high fat intake (Stumpf et al. 2000; Rowland et al. 2000; Kilkkinen et al. 2001) and also by antibiotic use (Kilkkinen et al. 2002), most probably due to their effect on the gut microflora.

The observed associations between serum phyto-oestrogens and PCa risk may also have been influenced by the use of just one serum sample for each subject. A moderately high level of reliability over 2 years has been reported for serum enterolactone measurements (reliability coefficient $=0.55$ ), but not for isoflavone serum measurements (reliability coefficients $\leq 0 \cdot 30$ ) (Zeleniuch-Jacquotte et al. 1998). This level of reliability of serum enterolactone measurements suggests a reasonable degree of long-term stability for intra-individual serum enterolactone levels, thereby suggesting that one serum measurement may be sufficient to estimate long-term average levels for epidemiological studies, although estimated relative risks may be attenuated. The lack of long-term reliability for isoflavone serum measurements may be another reason for the absence of an observed association between serum isoflavone concentrations and PCa risk in this study, as the one serum measurement used in this study may not be an accurate indicator of long-term serum levels of isoflavones. However, the lack of an observed association between isoflavone intake and $\mathrm{PCa}$ risk may confirm a true lack of effect on PCa risk for serum isoflavones.

In conclusion, our findings on a population of Scottish men support the hypotheses that serum enterolactone and soy food consumption protect against PCa risk. Interestingly enough, an association between $\mathrm{PCa}$ risk and isoflavone intake or serum concentrations was not found. In the light of these findings, future retrospective studies investigating the association between PCa risk and phyto-oestrogen intake and serum should include subjects with a greater variation of phyto-oestrogen and/or soy food intake. Such studies should also assess dietary intake of lignan precursors and its potential relationship with PCa risk.

\section{Acknowledgements}

The authors thank Dr Geraldine McNeil and colleagues for their support with the SCG-FFQ, and Polly Sommerville and Morag Leitch for their help with the subject recruitment, FFQ scanning and data collection. This study was part of the PCANDIET Study, supported jointly by CSA 4718 from the Food Standards Agency and Cancer Research UK (grant number SP2428/0101).

\section{References}

Adlercreutz H \& Mazur W (1997) Phyto-oestrogens and Western disease. Ann Med 29, 95-120.

Akaza H, Miyanaga N, Takashima N, Naito S, Hirao Y, Tsukamoto T $\&$ Mori M (2002) Is daidzein non-metabolizer a high risk for prostate cancer? A case-controlled study of serum soybean isoflavone concentration. Jpn J Clin Oncol 32, 296-300.

Arai Y, Uehara M, Sato Y, Kimira M, Eboshida A, Adlercreutz H \& Watanabe S (2000) Comparison of isoflavones among dietary intake, plasma concentration and urinary excretion for accurate estimation of phytoestrogen intake. J Epidemiol 10, 127-135.

Armstrong B \& Doll R (1975) Environmental factors and cancer incidence and mortality in different countries with special reference to dietary practices. Int $J$ Cancer 15, 617-631.

Bolton-Smith C, Woodward M, Fenton S, McCluskey MK \& Brown CA (1995) Trans fatty acids in the Scottish diet. An assessment using a semi-quantitative food-frequency questionnaire. $\mathrm{Br} J$ Nutr 74, 661-670.

Carstairs V \& Morris R (1991) Deprivation and Health in Scotland. Aberdeen: Aberdeen University Press.

Chan W, Brown J \& Buss DH (1994) Miscellaneous Foods: Fourth Supplement to the 5th Edition of McCance and Widdowson's The Composition of Foods. Cambridge: Royal Society of Chemistry.

Chan W, Brown J, Church SM \& Buss DH (1996) Meat Products and Dishes: Sixth Supplement to the 5th Edition of McCance and Widdowson's The Composition of Foods. Cambridge: Royal Society of Chemistry.

Chan W, Brown J \& Lee SM (1995) Meat, Poultry and Game: Fifth Supplement to the 5th Edition of McCance and Widdowson's The Composition of Foods. Cambridge: Royal Society of Chemistry.

Chen YC, Chiang CI, Lin RS, Pu YS, Lai MK \& Sung FC (2005) Diet, vegetarian food and prostate carcinoma among men in Taiwan. Br J Cancer 93, 1057-1061.

Chen Z, Zheng W, Custer LJ, Dai Q, Shu X-O, Jin F \& Franke AA (1999) Usual dietary consumption of soy foods and it correlation with the excretion rate of isoflavones in overnight urine samples among Chinese women in Shanghai. Nutr Cancer 33, 82-87.

Coward L, Barnes NC, Setchell KD \& Barnes S (1993) Genistein, daidzein, and their beta-glycoside conjugates - antitumor isoflavones in soybean foods from American and Asian diets. J Agric Food Chem 41, 1961-1967.

Goldberg GR, Black AE, Jebb SA, Cole TJ, Murgatroyd PR, Coward WA \& Prentice AM (1991) Critical evaluation of energy intake data using fundamental principles of energy physiology: 1. Derivation of cut-off limits to identify under-recording. Eur J Clin Nutr 45, 569-581.

Griffiths K, Denis L, Turkes A \& Morton MS (1998) Possible relationship between dietary factors and pathogenesis of prostate cancer. Int J Urol 5, 195-213.

Guess HA (2001) Benign prostatic hyperplasia and prostate cancer. Epidemiol Rev 23, 152-158.

Heald CL, Bolton-Smith C, Ritchie MR, Morton MS \& Alexander FE (2005) Phyto-oestrogen intake in Scottish men: use of serum to validate a self-administered food-frequency questionnaire in older men. Eur J Clin Nutr 60, 129-135.

Hodge AM, English DR, McCredie MRE, Severi G, Boyle P, Hopper JL \& Giles GG (2004) Foods, nutrients and prostate cancer. Cancer Causes Control 15, 11-20.

Holland B, Brown J \& Buss DH (1993) Fish and Fish Products: Third Supplement to the 5th Edition of McCance and Widdowson's 
The Composition of Foods. Cambridge: Royal Society of Chemistry.

Holland B, Welch A \& Buss DH (1988) Cereals and Cereal Products: Third Supplement to the 4th Edition of McCance and Widdowson's The Composition of Foods. Cambridge: Royal Society of Chemistry.

Holland B, Welch A \& Buss DH (1989) Milk Products and Eggs: Fourth Supplement to the 4th Edition of McCance and Widdowson's The Composition of Foods. Cambridge: Royal Society of Chemistry.

Holland B, Welch A \& Buss DH (1991a) Vegetables, Herbs and Spices: Fifth Supplement to the 4th Edition of McCance and Widdowson's The Composition of Foods. Cambridge: Royal Society of Chemistry.

Holland B, Welch A \& Buss DH (1992a) Fruit and Nuts: First Supplement to the 5th Edition of McCance and Widdowson's The Composition of Foods. Cambridge: Royal Society of Chemistry.

Holland B, Welch A \& Buss DH (1992b) Vegetable Dishes: Second Supplement to the 5th Edition of McCance and Widdowson's The Composition of Foods. Cambridge: Royal Society of Chemistry.

Holland B, Welch A, Unwin ID, Buss DH, Paul AA \& Southgate DAT (1991b) McCance and Widdowson's The Composition of Foods, 5th ed. Cambridge: Royal Society of Chemistry.

Horn-Ross PL, Barnes S, Lee M, Coward L, Mandel E, Koo J, John EM \& Smith M (2000a) Assessing phytoestrogen exposure in epidemiologic studies: development of a database (United States). Cancer Causes Control 11, 289-298.

Horn-Ross PL, Lee M, John EM \& Koo J (2000b) Sources of phytoestrogen exposure among non-Asian women in California, USA. Cancer Causes Control 11, 299-302.

Hsing AW, McLaughlin JK, Hrubec Z, Blot WJ \& Fraumeni JF Jr (1991) Tobacco use and prostate cancer: 26-year follow-up of US veterans. Am J Epidemiol 133, 437-441.

Hsing AW, McLaughlin JK, Schuman LM, Bjelke E, Gridley G, Wacholder S, Chien HT \& Blot WJ (1990) Diet, tobacco use, and fatal prostate cancer: results from the Lutheran Brotherhood Cohort Study. Cancer Res 50, 6836-6840.

ISD Scotland (2004) Cancer in Scotland Summary. Scottish Cancer Registry, NHS Scotland. http://www.isdscotland.org/isd/files/ Cancer_in_Scotland_summary_m.pdf

Jacobsen BK, Knutsen SF \& Fraser GE (1998) Does high soy milk intake reduce prostate cancer incidence? The Adventist Health Study (United States). Cancer Causes Control 9, 553-557.

Key TJ, Silcocks PB, Davey GK, Appleby PN \& Bishop DT (1997) A case-control study of diet and prostate cancer. Br J Cancer 76, $678-687$

Kilkkinen A, Pietinen P, Klaukka T, Virtamo J, Korhonen P \& Adlercreutz H (2002) Use of oral antimicrobials decreases serum enterolactone concentration. Am J Epidemiol 155, 472-477.

Kilkkinen A, Stumpf K, Pietinen P, Valsta LM, Tapanainen H \& Adlercreutz H (2001) Determinants of serum enterolactone concentration. Am J Clin Nutr 73, 1094-1100.

Kilkkinen A, Virtamo J, Virtanen MJ, Adlercreutz H, Albanes D \& Pietinen P (2003) Serum enterolactone concentration is not associated with prostate cancer risk in a nested case-control study. Cancer Epidemiol Biomarkers Prev 12, 1209-1212.

Kirk D \& Alexander FE (2001) Prostate cancer. In Cancer Scenarios: An Aid to Planning Cancer Services in Scotland in the Next Decade, pp. 150-158 [RJ Black and D Stockton, editors]. Edinburgh: The Scottish Executive.

Kolonel LN (2001) Fat, meat, and prostate cancer. Epidemiol Rev 23, $72-81$.

Kolonel LN, Hankin JH, Whittenmore AS, et al. (2000) Vegetables, fruits, legumes and prostate cancer: a multiethnic case-control study. Cancer Epidemiol Biomarkers Prev 9, 795-804.

Kuzer MS \& Xu X (1997) Dietary phytoestrogens. Anпu Rev Nutr 17, $353-381$
Lee MM, Gomez SL, Chang JS, Wey M, Wang RT \& Hsing AW (2003) Soy and isoflavone consumption in relation to prostate cancer risk in China. Cancer Epidemiol Biomarkers Prev 12, 665-668.

Liggins J, Bluck LJ, Runswick S, Atkinson C, Coward WA \& Bingham SA (2000a) Daidzein and genistein contents of vegetables. Br J Nutr 84, 717-725.

Liggins J, Bluck LJ, Runswick S, Atkinson C, Coward WA \& Bingham SA $(2000 b)$ Daidzein and genistein content of fruits and nuts. $J$ Nutr Biochem 11, 326-331.

Liggins J, Grimwood R \& Bingham SA (2000c) Extraction and quantification of lignan phytoestrogens in food and human samples. Anal Biochem 287, 102-109.

Maskarinec G, Singh S, Meng L \& Franke AA (1998) Dietary soy intake and urinary isoflavone excretion among women from a multiethnic population. Cancer Epidemiol Biomarkers Prev 7, 613-619.

Masson LF, McNeill G, Tomany JO, Simpson JA, Peace HS, Wei L, Grubb DA \& Bolton-Smith C (2003) Statistical approaches for assessing the relative validity of a food-frequency questionnaire: use of correlation coefficients and the kappa statistic. Public Health Nutr 6, 313-321.

Mazur W (1998) Phytoestrogen content in foods. Bailliere's Clin Endocrinol Metab 12, 729-742.

Mills PK, Beeson WL, Phillips RL \& Fraser GE (1989) Cohort study of diet, lifestyle, and prostate cancer in Adventist men. Cancer 64, 598-604.

Morton MS, Arisaka O, Miyake N, Morgan LD \& Evans BA (2002) Phytoestrogen concentrations in serum from Japanese men and women over forty years of age. $J$ Nutr 132, 3168-3171.

Morton MS, Wilcox G, Wahlqvist ML \& Griffiths K (1994) Determination of lignans and isoflavonoids in human female plasma following dietary supplementation. $J$ Endocrinol 142, 251-259.

Muir CS, Nectoux J \& Staszewski J (1991) The epidemiology of prostatic cancer: geographical distribution and time-trends. Acta Oncol 30, $133-140$.

Murphy PA, Song T, Buseman G, Barua K, Beecher GR, Trainer D \& Holden J (1999) Isoflavones in retail and institutional soy foods. J Agric Food Chem 47, 2697-2704.

Ozasa K, Nakao M, Watanabe Y, et al. (2004) Serum phytoestrogens and prostate cancer risk in a nested case-control study among Japanese men. Cancer Sci 95, 65-71.

Parkin DM \& Muir CS (1992) Comparability and quality of data. In Cancer Incidence in Five Continents, pp. 45-173 Lyon: IARC Scientfic Publications.

Pillow PC, Duphorne CM, Chang S, Contois JH, Strom SS, Spitz MR \& Hursting SD (1999) Development of a database for assessing dietary phytoestrogen intake. Nutr Cancer 33, 3-19.

Ritchie MR (2004) Isoflavone Food Database. http://medicine. st-andrews.ac.uk/research/docs/ritchie/

Ritchie MR, Cummings JH, Morton MS, Steel CM, Bolton-Smith C $\&$ Riches AC (2005) A newly constructed and validated isoflavone database for the assessment of total genistein and daidzein intake. Br J Nutr 95, 204-213.

Ritchie MR, Morton MS, Deighton N, Blake A \& Cummings JH (2004) Plasma and urinary phyto-oestrogens as biomarkers of intake: validation by duplicate diet analysis. Br J Nutr 91, 447-457.

Rowland I, Wiseman H, Sanders T, Adlercreutz H \& Bowey E (1999) Metabolism of oestrogens and phytoestrogen: role of the gut microflora. Biochem Soc Trans 27, 304-308.

Rowland IR, Wiseman H, Sanders TAB, Adlercreutz H \& Bowey EA (2000) Interindividual variation in metabolism of soy isoflavones and lignans: influence of habitual diet on equol production by the gut microflora. Nutr Cancer 36, 27-32.

Schofield WN (1985) Predicting basal metabolic rate, new standards and review of previous work. Hum Nutr-Clin Nutr 39, Suppl 1, $5-41$. 
Severson RK, Nomura AMY, Grove JS \& Stemmermann GN (1989) A prospective study of demographics, diet and prostate cancer among men of Japanese ancestry in Hawaii. Cancer Res 49, $1857-1860$.

Sharp L, Little J, Brockton N, Cotton SC, Haites NE \& Cassidy J (2002) Intake of folate and related micronutrients, genetic polymorphisms in MTHFR and colorectal cancer: a population-based case-control study in Scotland. J Nutr 132, 3542S.

Stattin P, Adlercreutz H, Tenkanen L, et al. (2002) Circulating enterolactone and prostate cancer risk: a Nordic nested case-control study. Int J Cancer 99, 124-129.

Stattin P, Bylund A, Biessy C, Kaaks R, Hallmans G \& Adlercreutz H (2004) Prospective study of plasma enterolactone and prostate cancer risk (Sweden). Cancer Causes Control 15, 1095-1102.

Strom SS, Yamamura Y, Duphorne CM, Spitz MR, Babaian RJ, Pillow PC \& Hursting SD (1999) Phytoestrogen intake and prostate cancer: a case-control study using a new database. Nutr Cancer 33, 20-25.

Stumpf K, Pietinen P, Puska P \& Adlercreutz H (2000) Changes in serum enterolactone, genistein, and daidzein in a dietary intervention study in Finland. Cancer Epidemiol Biomarkers Prev 9, 1369-1372.
USDA (1999) USDA (United States Department of Agriculture) Iowa State University database on the isoflavone content of foods. USDA. www.nal.usda.gov/fnic/foodcomp/Data/isoflav/isoflav.html

Venus Phyto-oestrogen Database (2004) Venus. www.venus-ca.org Villeneuve PJ, Johnson KC, Kreiger N \& Mao Y (1999) Risk factors for prostate cancer: results from the Canadian National Enhanced Cancer Surveillance System. The Canadian Cancer Registries Epidemiology Research Group. Cancer Causes Control 10, 355-367.

Wakai K, Egami I, Kato K, Kawamura T, Tamakoshi A, Lin Y, Nakayama T, Wada M \& Ohno Y (1999) Dietary intake and sources of isoflavones among Japanese. Nutr Cancer 33, 139-145.

Willett WC \& Stampfer MJ (1998) Implications of total energy intake for epidemiologic analyses. In Nutritional Epidemiology, pp. 273-301 [WC Willett, editor]. New York: Oxford University Press.

Yan L \& Spitznagel EL (2005) Meta-analysis of soy food and risk of prostate cancer in men. Int $J$ Cancer 117, 667-669.

Zeleniuch-Jacquotte A, Adlercreutz H, Akhmedkhanov A \& Toniolo P (1998) Reliablity of serum measurements of lignans and isoflavonoid phytoestrogens over a two-year period. Cancer Epidemiol Biomarkers Prev 7, 885-889. 